Research Article

\title{
Seepage Property of Crushed Mudstone Rock in Collapse Column
}

\author{
Bo-Yang Zhang and Zhi-Bin Lin $(1)$ \\ School of Civil Engineering, Henan Polytechnic University, Jiaozuo 454000, China \\ Correspondence should be addressed to Zhi-Bin Lin; linzhibin@hpu.edu.cn
}

Received 3 March 2020; Accepted 2 May 2020; Published 15 May 2020

Academic Editor: Zhi-Qiang Yin

Copyright (C) 2020 Bo-Yang Zhang and Zhi-Bin Lin. This is an open access article distributed under the Creative Commons Attribution License, which permits unrestricted use, distribution, and reproduction in any medium, provided the original work is properly cited.

\begin{abstract}
The karst collapse column composed of crushed rocks and fine argillaceous or clay particles is easy to form the fissure channels between the coal seam working face and the confined limestone aquifer under mining and causes water inrush disasters with the loss of underground water resource, economic losses, and casualties. It is of great necessity to understand the seepage properties of crushed rock in karst collapse column for the prevention of water inrush and the protection of underground water resource. A self-developed seepage test system is used in this paper to conduct laboratory experiments on seepage properties of crushed mudstone specimens. The effects of the particle size distribution, the porosity (specimen height), and the hydraulic pressure on the water flow velocity and the permeability of crushed specimen are analyzed. The results indicate that the permeability of specimen increases with the particle size, porosity, and hydraulic pressure. It can be known from the comparative experiments of progressive hydraulic pressure on one specimen and variable hydraulic pressure on different specimens with constant particle size and porosity that more fine particles leak out from the specimen with repeated application of hydraulic pressure on one specimen. Therefore, the permeability of one specimen is bigger than that of different specimens under the condition of same hydraulic pressure.
\end{abstract}

\section{Introduction}

The karst collapse column is a special geological structure widely distributed in North China, which is composed of fillings such as crushed rocks and fine argillaceous or clay particles. In the process of coal mining in these areas, it is easy to form the fissure channels between the coal seam working face and the confined limestone aquifer (Figure 1), thereby causing water inrush disasters which results in the loss of underground water resource, economic losses, and casualties [1-3]. Therefore, it is of great significance to study the seepage property of this special geological material [4-6].

At present, there are few experiments on this special geological material. The collapse column is easy to disintegrate under disturbance, which causes the difficulty to drill an intact sample. Meanwhile, the sampling of collapse column may result in the water inrush disasters on site. Hence, most experimental researches were carried out on the crushed rocks and fine clay particles to describe the seepage property of collapse column [7]. Liu et al. [8] obtained the relation between the axial stress and the permeability of broken rock through the steady-state seepage experiment. In fact, the external axial stress affected the seepage behavior of broken rock by changing its structure such as fissure channels. In addition to the effect of external stress, the role of hydraulic pressure on the structure was also worthy of attention. So Miao et al. constructed the nonlinear dynamic flow theory for describing the non-Darcy flow within broken rock $[9,10]$. Based on this theory, the effects of porosity and particle size on the non-Darcy flow parameters of crushed rock were investigated $[11,12]$. In addition, $\mathrm{Ma}$ et al. considered that the lithology of rock was an important factor to affect the non-Darcy flow property of crushed rock [13]; then the seepage properties of crushed mudstone, limestone, and sandstone under different porosities and particles sizes were studied [14]. The above studies focused on the nonlinear seepage behavior of crushed rocks; the erosion inside the structure was not taking full account. During the mining process, on the one hand, the fracture network of the rock mass is fully developed under the action of disturbance. On 


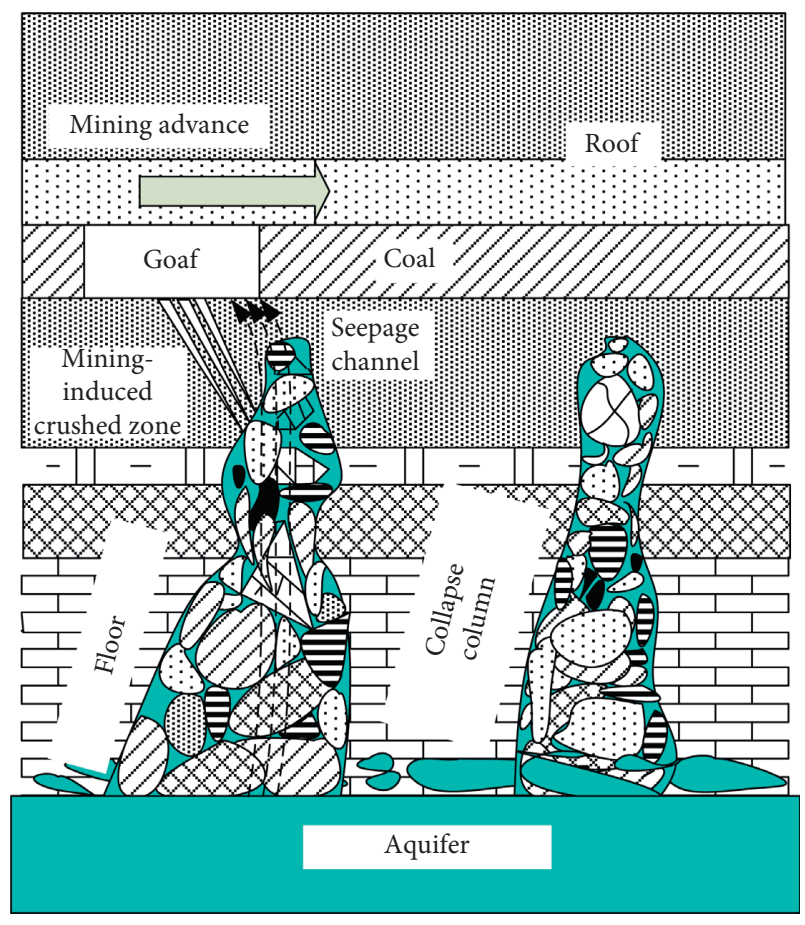

FIGURE 1: Seepage channel of collapse column under mining.

the other hand, the fine particles absorb water and swell to deteriorate the fracture structure of the rock mass. Under the effect of underground confined water, these fine particles are easily dissolved with water, and the two-phase fluid composed of fine particles and water migrates and is lost in the fracture network of collapse column to further expand its channels. When the small particles with cohesive effect are lost to a certain extent, the framework structure of the collapse column is failed to cause the water inrush disaster with sharp increase of seepage velocity. Garner and Fannin [15] considered that the material susceptibility, hydraulic load, and stress condition were the key factors of this erosion. Marot et al. [16] indicated that the erosion of clay and sand causes the failure of the structure under high gradients. Ke and Takahashi [17] proved that the fine particles in structure gradually migrate through the voids among the coarse particles, which results in the porous framework with low strength. Obviously, the erosion inside the structure should also be related to time; even under low hydraulic pressure, the long-term effect of erosion can also cause the seepage mutation [18]. It can be seen that the research about the seepage behavior of collapse column should consider both its nonlinearity and erosion.

A large amount of coal is distributed in North China [19-21]. Most of the collapse columns in the areas with high risk of water inrush are in the consolidation state. The fine argillaceous or clay particles are an important factor influencing the seepage characteristics of collapse column [22-24]. However, the seepage properties of crushed mudstone were rarely carried out in the above study. In addition, previous study of collapse column focused on the particle size mixture, and no study on fine particles of the single range has been reported to fill this study gap. The seepage behavior of the collapse column is unclear. Therefore, the crushed mudstone with different single particle size ranges was sampled to obtain fine particles material in this paper. The seepage test was carried out to understand its seepage behavior. The laws of flow velocity that varied with particle size range, specimen height (porosity), hydraulic pressure, and time were analyzed during the seepage. The relation between the permeability and porosity was obtained.

\section{Experimental Method}

2.1. Experimental Material and System. The experimental material is crushed mudstone (Figure 2).

The experimental system for testing the seepage property of crushed rock was designed as shown in Figure 3, which was comprised of four parts: (A) hydraulic pressure system, (B) axial displacement system, (C) permeability system, and (D) data acquisition and analysis system.

(A) Hydraulic pressure system was used to provide hydraulic pressure for the specimens. This system was composed of oil pump, water pump, dual-acting hydraulic cylinder, connection pipeline, and globe valve.

(B) Axial displacement system can load and control axial displacement and provide axial pressure for the specimens to control the porosity of the specimens.

(C) Permeability system was used to test the seepage property of crushed rock. It was composed of a permeameter, a pallet, and an overflow tube.

(D) Data acquisition and analysis system was used to obtain the seepage and mechanical parameters including hydraulic pressure, oil pressure, flow rate, axial stress, and axial displacement, and it was composed of a pressure sensor, a mass flowmeter, a data acquisition system, and a computer.

2.2. Experimental Procedures. The experimental procedures are as follows:

(1) Crushed mudstone specimen with fixed particle size range (Table 1) and piston (Figure 3 ) were placed into the permeameter successively, and then the percolation cylinder was put into the base (substructure).

(2) The permeability system was placed on the material testing system (MTS) 816 experimental table, and the piston was lowered by MTS 816 to compress the specimen to a fixed height for controlling the porosity of the specimen (Table 1 ).

(3) We added water into the dual-acting hydraulic cylinder by the water pump (Figure 3), closed the globe valve between dual-acting hydraulic cylinder and water pump, and opened the globe valve between dual-acting hydraulic cylinder and the permeameter. The constant hydraulic pressure (Table 1) in the dual-acting hydraulic cylinder was injected 


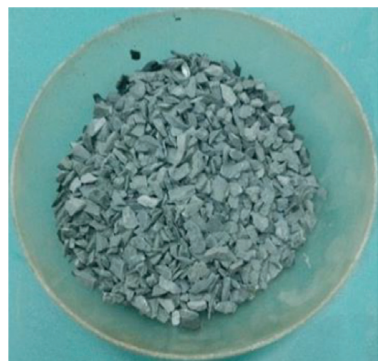

(a)

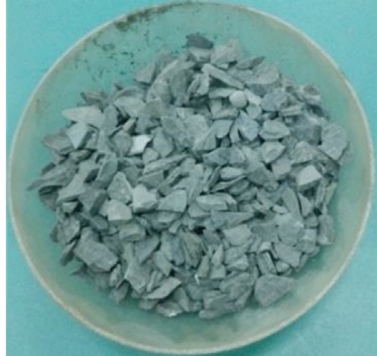

(b)

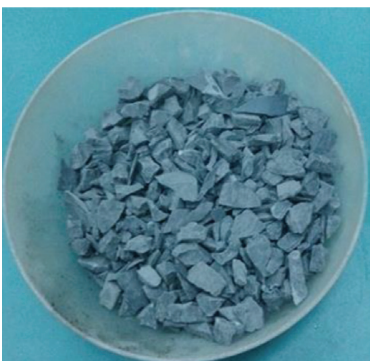

(c)

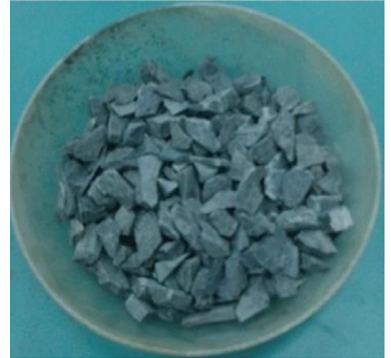

(d)

Figure 2: Experimental materials. (a) $5.0 \mathrm{~mm} \sim 7.5 \mathrm{~mm}$. (b) $7.5 \mathrm{~mm} \sim 10.0 \mathrm{~mm}$. (c) $10.0 \mathrm{~mm} \sim 12.5 \mathrm{~mm}$. (d) $12.5 \mathrm{~mm} \sim 15.0 \mathrm{~mm}$.

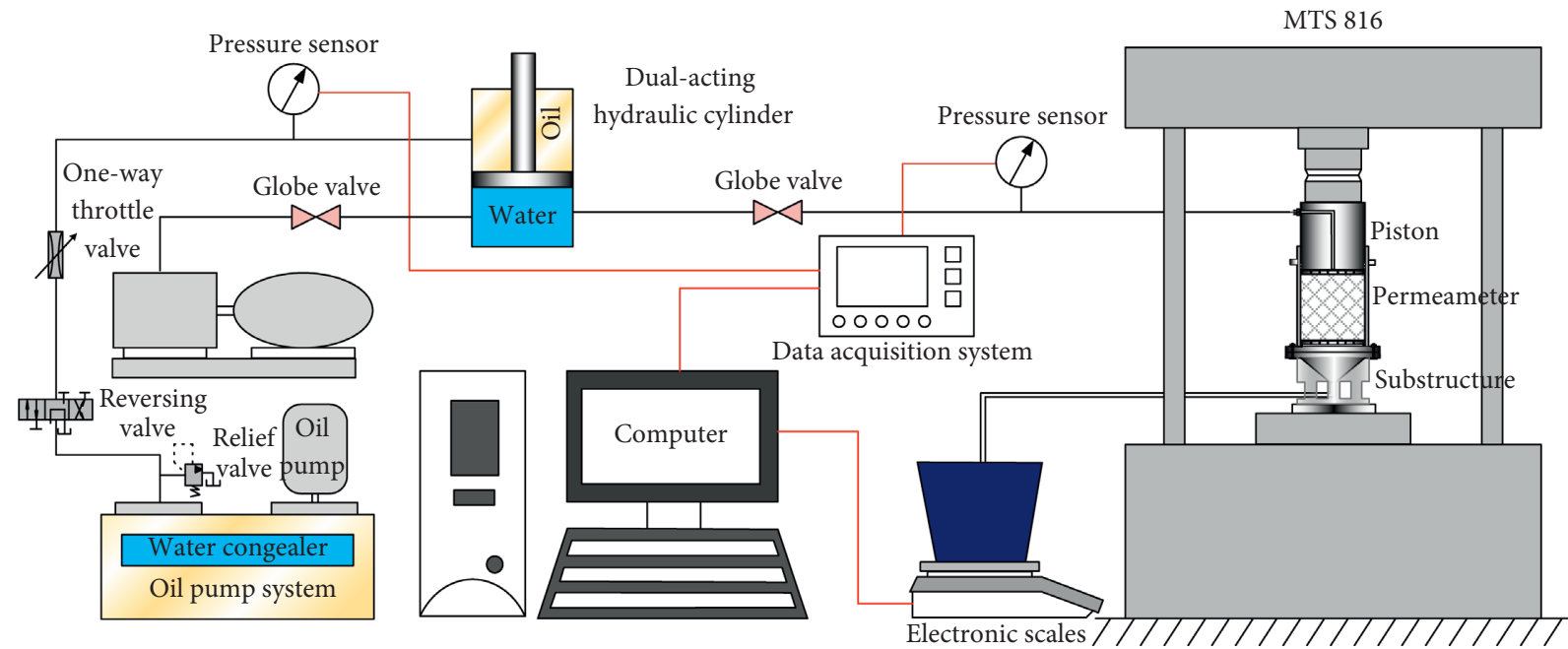

Figure 3: Experimental system [25].

TABLE 1: Experimental program.

\begin{tabular}{|c|c|c|c|c|}
\hline Specimen group & Specimen no. & Particle size $(\mathrm{mm})$ & Porosity & Hydraulic pressure $(\mathrm{MPa})$ \\
\hline \multirow{4}{*}{1} & $1 \mathrm{a}$ & $5.0 \sim 7.5$ & 0.19 & 0.7 \\
\hline & $1 b$ & $7.5 \sim 10.0$ & 0.19 & 0.7 \\
\hline & $1 \mathrm{c}$ & $10.0 \sim 12.5$ & 0.19 & 0.7 \\
\hline & $1 d$ & $12.5 \sim 15.0$ & 0.19 & 0.7 \\
\hline \multirow{4}{*}{2} & $2 \mathrm{a}$ & $10.0 \sim 12.5$ & 0.15 & 0.7 \\
\hline & $2 b$ & $10.0 \sim 12.5$ & 0.19 & 0.7 \\
\hline & $2 c$ & $10.0 \sim 12.5$ & 0.23 & 0.7 \\
\hline & $2 \mathrm{~d}$ & $10.0 \sim 12.5$ & 0.27 & 0.7 \\
\hline \multirow{4}{*}{3} & $3 a$ & $7.5 \sim 10.0$ & 0.19 & 0.3 \\
\hline & $3 b$ & $7.5 \sim 10.0$ & 0.19 & 0.7 \\
\hline & $3 c$ & $7.5 \sim 10.0$ & 0.19 & 1.1 \\
\hline & $3 d$ & $7.5 \sim 10.0$ & 0.19 & 1.5 \\
\hline
\end{tabular}

into the permeameter by means of the oil pump. The test began.

(4) The seepage and mechanical parameters including hydraulic pressure, oil pressure, flow rate, axial stress, and axial displacement were recorded by the data acquisition system (Figure 3).

\subsection{Calculation Theory}

2.3.1. The Calculation Method of Velocity. The velocity is calculated as follows:

$$
v_{j, t=i}=\frac{M_{j, t=i}-M_{j, t=i-1}}{\rho A_{s}},
$$


where $v_{k, t=i}$ is the velocity of specimen no. $j$ in Table $1, \mathrm{~m} / \mathrm{s}$, $M_{k}$ is the water loss mass of specimen no. $j, \mathrm{~kg}, \rho$ is the density of water, which is assumed to be $1,000 \mathrm{~kg} / \mathrm{m}^{3}$ as the experiments are carried out at room temperature, and $A_{s}$ is cross-section area of permeameter, which is $7.85 \times 10^{-3} \mathrm{~m}^{2}$.

2.3.2. The Calculation Method of Permeability. The permeability is calculated by Darcy equation as follows:

$$
\frac{\Delta p_{j}}{\Delta h_{j}}=-\frac{\mu}{k_{j}} v_{j}
$$

where $\Delta p_{j}$ is the hydraulic pressure difference between the two ends of the specimen no. $j, \mathrm{MPa}, \Delta h_{j}$ is the height of specimen no. $j, k_{j}$ is the permeability of specimen no. $j, \mathrm{~m}^{2}$, and $\mu$ is the dynamic viscosity of water, which is assumed to be $1.01 \times 10^{-3} \mathrm{~Pa} \cdot \mathrm{s}$.

2.3.3. The Calculation Method of Porosity. The porosity is calculated as follows:

$$
\varphi_{j}=\frac{A_{S} \Delta h_{j}-V_{b}}{A_{S} \Delta h_{j}},
$$

where $\varphi_{j}$ is the porosity of specimen no. $k$ and $V_{b}$ is the volume of crushed rock, which is $9.03 \times 10^{-4} \mathrm{~m}^{3}$.

\section{Experimental Results and Discussion}

3.1. Particle Size. Specimen no. 1a was taken as an example to illustrate the calculation process of flow velocity. We measured the variation curve of water mass with time in the experiment as shown in Figure 4 and calculated the variation curve of water flow velocity with time (Figure 4 ) by (1). The permeability of the specimen was calculated by (2). The curves of hydraulic pressure and permeability of the first group (Table 1) over time are shown in Figure 5. Figures 5(c) and 5(d) are taken as examples to illustrate the seepage experimental process. We recorded the hydraulic pressure and water mass while opening the oil pump. In the first stage, the hydraulic pressure gradually increased after the experiment initiation. The water flowed rapidly into the seepage cylinder, forming a water hammer effect to impact on the specimen, and the water mass flowing out from outlet increased rapidly. The water leaking out from the outlet appeared black at the beginning of the experiment, gradually turned gray, and finally turned clear. With the weakening of water hammer, the flow rate and hydraulic pressure tended to be stable (i.e., stable seepage stage). However, seepage mutation often occurs in the overall experimental process. In Figure 5(d), we can find that when the experiment started at $180 \sim 190 \mathrm{~s}$, the flow rate rapidly increased and the hydraulic pressure slightly decreased, with a small amount of fine particles flowing out from the outlet. At this time, the water leaking out from the outlet appeared black. Before the seepage mutation occurred, the water pipe connected to the inlet twitched slightly. When the experiment was carried out to about $500 \mathrm{~s}$, a rapid increase of the flow rate and a rapid decrease of the hydraulic pressure occurred, accompanied by

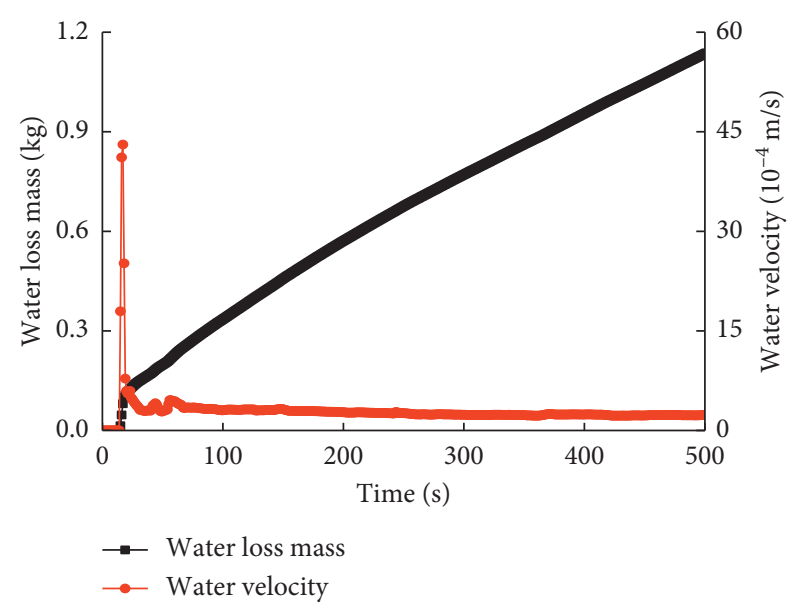

FIGURE 4: Water loss mass and velocity of specimen no. 1a variation curves with time.

a large number of fine particles leaking from outlet, resulting in a significant seepage mutation. In order to ensure the safety of the experimenter, the test is usually terminated quickly when the seepage mutation occurs.

For this experiment, the average permeability in the stable seepage stage without seepage mutation stage was taken as the permeability of the specimen. The variation curve of permeability with particle size range number ( 1 for particle size range $5.0 \sim 7.5 \mathrm{~mm}, 2$ for particle size range $7.5 \sim 10.0 \mathrm{~mm}, 3$ for particle size range $10.0 \sim 12.5 \mathrm{~mm}$, and 4 for particle size range $12.5 \sim 15.0 \mathrm{~mm}$ ) is shown in Figure 6 . The permeability of the crushed mudstone was on the magnitude of $10^{-14} \mathrm{~m}^{2} \sim 10^{-13} \mathrm{~m}^{2}$. The permeability of particle size range numbers $1,2,3$, and 4 was $2.19 \times 10^{-14} \mathrm{~m}^{2}$, $4.74 \times 10^{-14} \mathrm{~m}^{2}, 19.55 \times 10^{-14} \mathrm{~m}^{2}$, and $42.17 \times 10^{-14} \mathrm{~m}^{2}$, respectively. Under the condition of constant porosity (0.19) and hydraulic pressure $(0.7 \mathrm{MPa})$, the permeability of the specimen increased with particle size range number. It may be due to two reasons: first, as the volume and porosity of crushed specimen were the same, there were less pore and bigger pore diameters in the specimen with big particle size range number, which resulted in more effective seepage channels in this specimen. So the specimen with big particle size range number demonstrated higher permeability. Second, the specimen with small particle size range number was composed of more fine particles, which expanded with water and blocked the seepage channels of crushed rock specimen. Therefore, the specimen with small particle size range number showed lower permeability.

3.2. Porosity. Figure 7 is hydraulic pressure and permeability (calculated by (2)) variation curves of second group specimens (Table 1) with time. As can be seen from Figure 7(d), when the water was injected into permeameter about $340 \mathrm{~s}$, the flow rate and hydraulic pressure decreased rapidly. This is because of the closing of the experimental instrument. The maximum range of the electronic balance used in the experiment was $5.2 \mathrm{~kg}$. Considering the mass of the water container, the experiment will be stopped when the mass of 


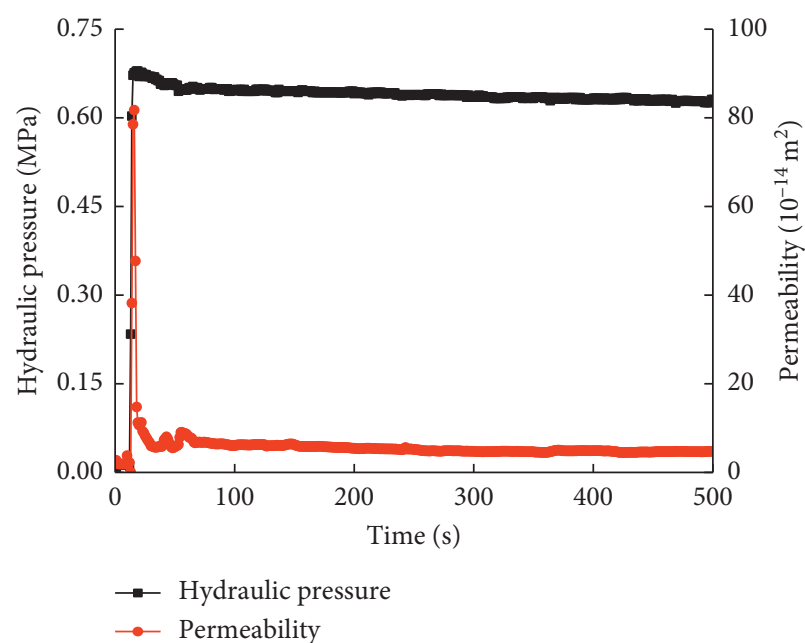

(a)

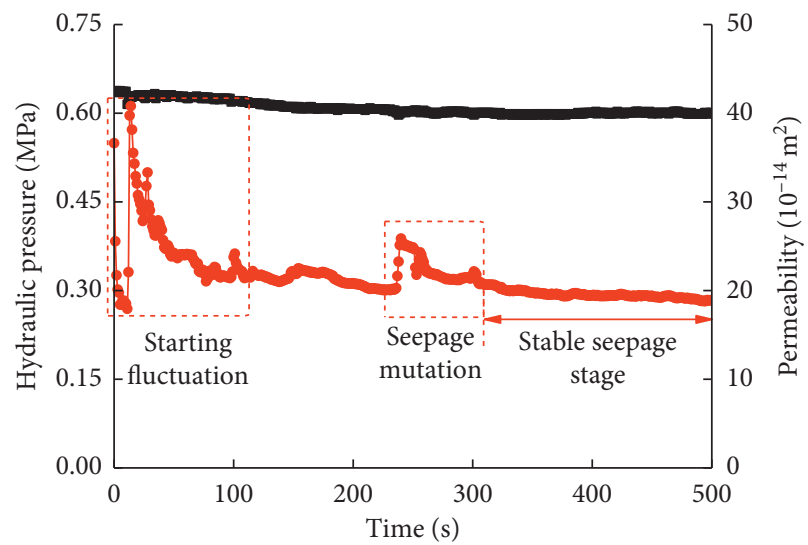

- Hydraulic pressure

$\rightarrow$ Permeability

(c)

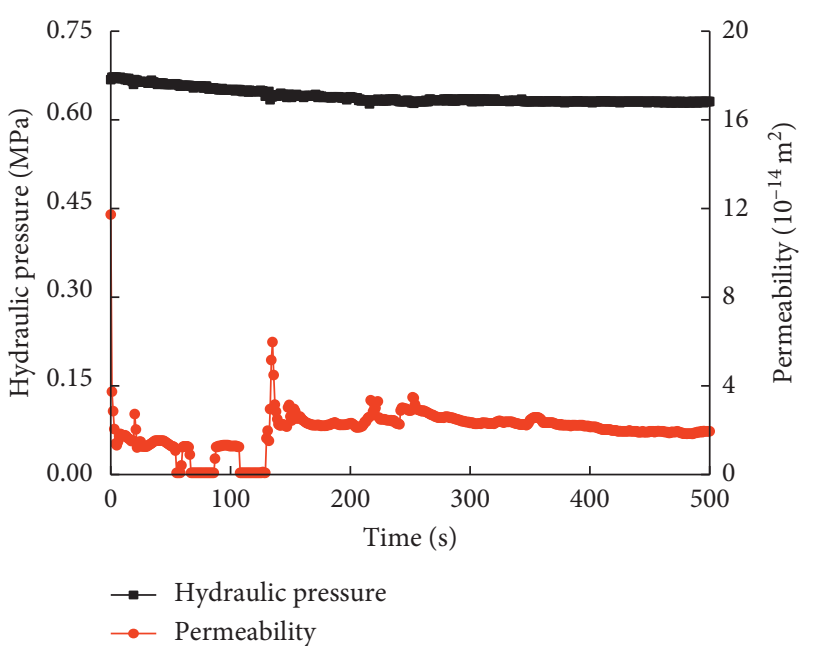

(b)

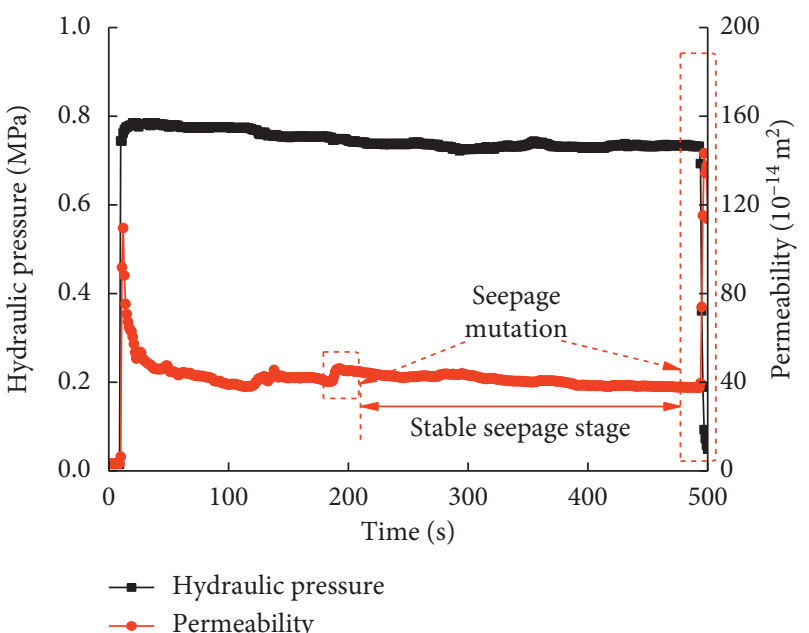

(d)

Figure 5: Hydraulic pressure and permeability variation curves of first group specimens with time. (a) $5.0-7.5 \mathrm{~mm}$. (b) $7.5-10.0 \mathrm{~mm}$. (c) $10.0-12.5 \mathrm{~mm}$. (d) $12.5-15.0 \mathrm{~mm}$.

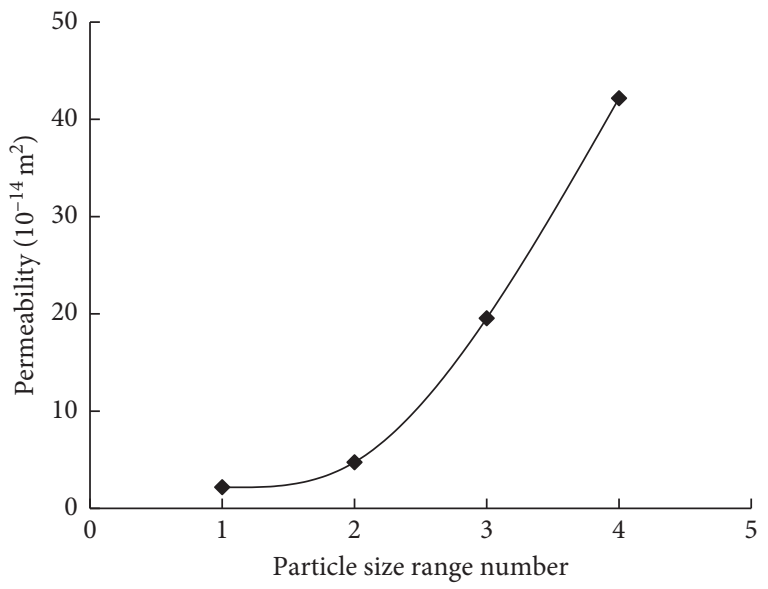

Figure 6: Permeability variation curve with particle size range number. 


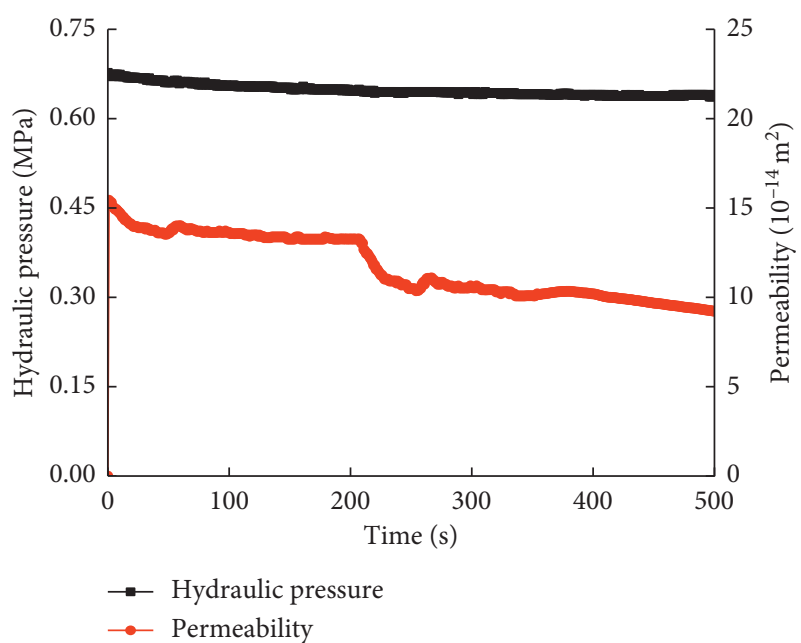

(a)

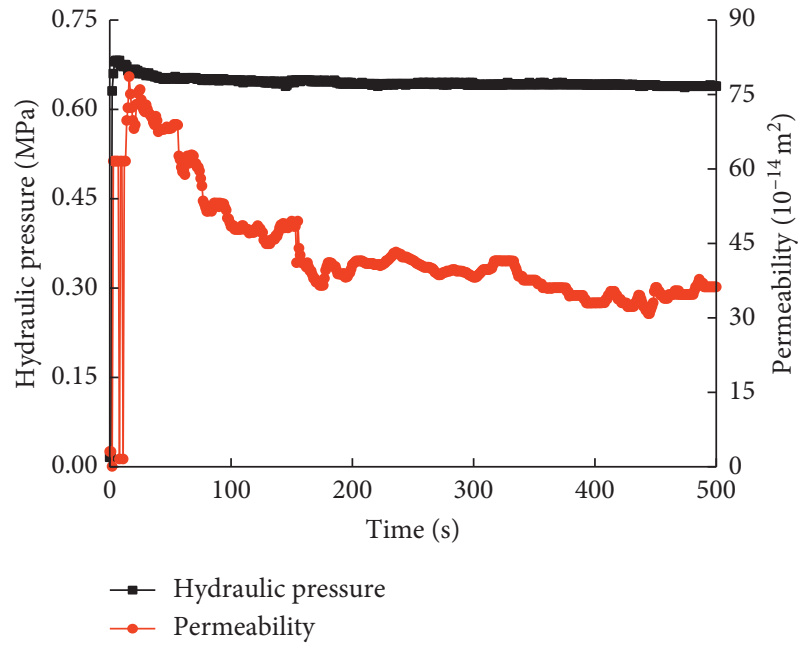

(c)

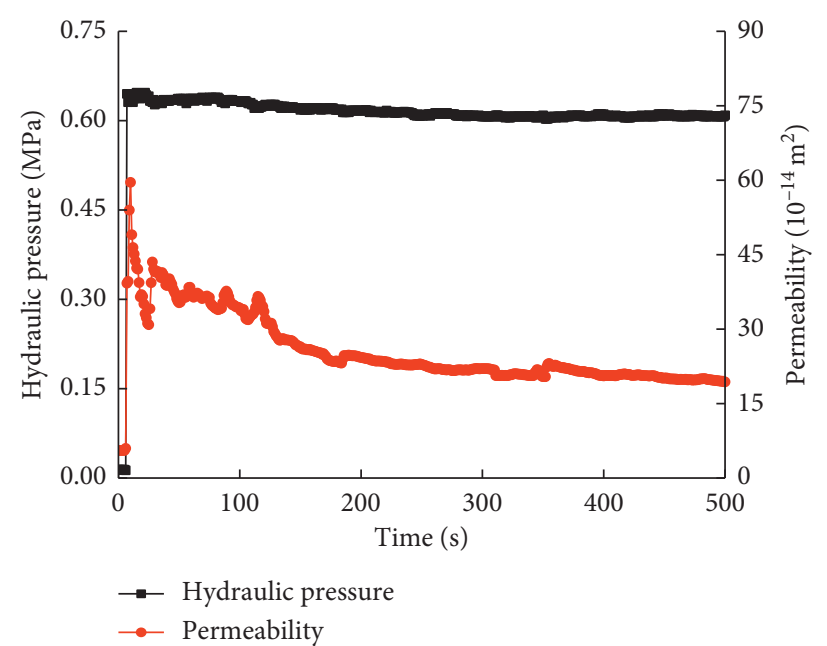

(b)

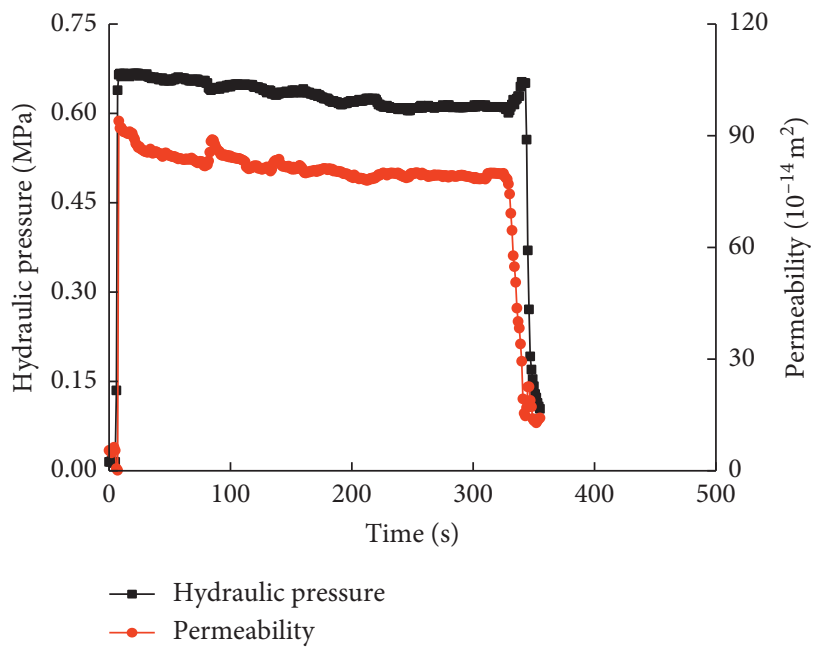

(d)

Figure 7: Hydraulic pressure and permeability variation curves of second group specimens with time. (a) 0.15 . (b) 0.19 . (c) 0.23 . (d) 0.27 .

the water flowing from outlet (in Figure 3) reached about $4.5 \mathrm{~kg}$. In contrast, the permeability of specimen no. $2 \mathrm{~d}$ (Table 1) is higher and the flow rate is faster in Figure $7(\mathrm{~d})$, and the experiment only lasted for $340 \mathrm{~s}$. However, the experiment of other specimens can usually last more than $500 \mathrm{~s}$.

The porosities of the specimens were calculated by (3). Figure 8 is permeability variation curve with porosity (the permeability was obtained from the average value of the stable stage in Figure 7). The porosities of specimens $2 a, 2 b$, $2 \mathrm{c}$, and $2 \mathrm{~d}$ (Table 1 ) were $0.15,0.19,0.23$, and 0.27 , respectively. The corresponding permeability of specimens was $9.97 \times 10^{-14} \mathrm{~m}^{2}, 19.92 \times 10^{-14} \mathrm{~m}^{2}, 39.31 \times 10^{-14} \mathrm{~m}^{2}$, and $79.89 \times 10^{-14} \mathrm{~m}^{2}$, respectively. Under the condition of constant hydraulic pressure $(0.7 \mathrm{MPa})$ and particle size $(10.0 \sim 12.5 \mathrm{~mm})$, permeability increased with the increase of porosity. A number of models have been developed for finding out the relationship of permeability and porosity [26-29]. The proportional coefficient of permeability $k_{k} / k_{0}$ was defined as ratio of permeability and minimum permeability in the following three models:

$$
\begin{aligned}
& \frac{k_{j}}{k_{0}}=\left(\frac{1-\varphi_{0}}{1-\varphi_{j}}\right)^{2}\left(\frac{\varphi_{j}}{\varphi_{0}}\right)^{3}, \\
& \frac{k_{j}}{k_{0}}=\left[\frac{\left(1-\varphi_{0}\right)\left(1.275-1.5 \varphi_{j}\right)}{\left(1-\varphi_{j}\right)\left(1.275-1.5 \varphi_{0}\right)}\right]^{2}\left(\frac{\varphi_{j}}{\varphi_{0}}\right)^{3}, \\
& \frac{k_{j}}{k_{0}}=\left(\frac{\varphi_{j}}{\varphi_{0}}\right)\left(\frac{1-\varphi_{0}}{1-\varphi_{j}}\right)^{2},
\end{aligned}
$$

where $k_{0}$ is the minimum permeability of second specimen group (which is $9.97 \times 10^{-14} \mathrm{~m}^{2}$ ) and $\varphi_{0}$ is the minimum porosity of second specimen group (which is 0.15 ).

The three models of (4)-(6) were fitted for indicating the relationship of permeability and porosity (Figure 9 ). The fitting correlation index $R^{2}$ [29] of (4)-(6) was 0.997, 0.919, and 0.579 , respectively. Therefore, it can be seen that the experimental materials of crushed mudstone adopted (4) in this paper. 


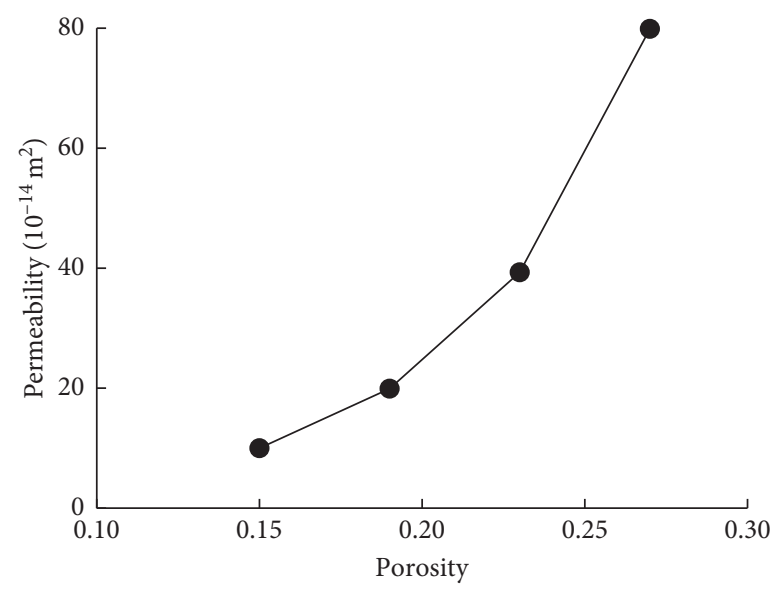

FIGURE 8: Permeability variation curve with porosity.

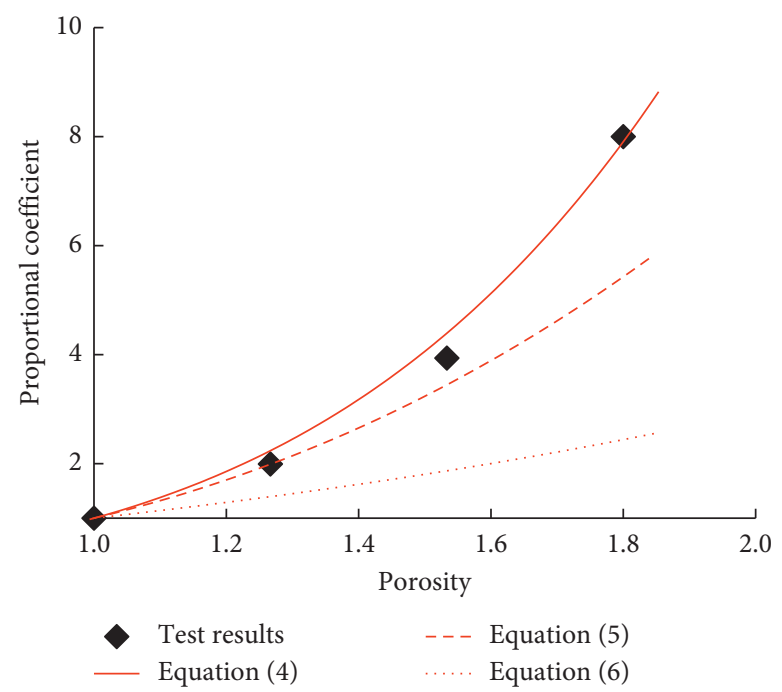

Figure 9: Proportional coefficient variation curve with porosity.

3.3. Hydraulic Pressure. Figure 10 is hydraulic pressure and permeability (calculated by (2)) variation curves of third group specimens (Table 1) with time. The particle size of the third group was $7.5 \sim 10.0 \mathrm{~mm}$ and the porosity was 0.19 . The initial hydraulic pressure was set to $0.3 \mathrm{MPa}, 0.7 \mathrm{MPa}$, 1.1 MPa, and 1.5 MPa, respectively. During the experiment, the head of the oil pump was kept unchanged, but the hydraulic pressure decayed gradually. The hydraulic pressure of specimens Nos. 3a, 3b, 3c, and 3d in the experiment decayed $9.6 \%, 8.6 \%, 5.8 \%$, and $4.3 \%$, respectively.

Figure 11 is permeability (calculated according to the average value of the stable seepage stage) and velocity (calculated by (1)) variation curves with hydraulic pressure. As can be seen from Figure 11, the velocity changed approximately linearly with the hydraulic pressure. It can be known from (2) that the hydraulic pressure and permeability of the specimen will remain the uniform growth proportion, as the specimen was under the condition of constant particle size range, porosity, dynamic viscosity, and specimen height. However, the hydraulic pressure in the experiment increased from about $0.3 \mathrm{MPa}$ to about $1.5 \mathrm{MPa}$ by a factor of 5.0, and the velocity in the experiment increased from $0.72 \times 10^{-4} \mathrm{~m} / \mathrm{s}$ to $9.12 \times 10^{-4} \mathrm{~m} / \mathrm{s}$, increasing by a factor of about 12.8 . Therefore, the permeability increased with hydraulic pressure in Figure 11. The reason may be that the water with different hydraulic pressure was repeatedly injected into the same specimen (i.e., this is only one specimen in the third specimen group). The fine particles were migrated to the bottom of the specimen and then leaked from the specimen into the outlet with water in each hydraulic pressure level. It resulted in the increase of the porosity in the specimen, and the permeability obviously increased. In order to find out the actual pressure-permeability law, further experiments were carried out with the specimen changed in every hydraulic pressure level. Figure 12 is permeability and velocity of different specimens with same particle size variation curves with hydraulic pressure. It can be seen from Figure 12 that permeability and velocity of variable specimen also increased with hydraulic pressure, which indicated that fine particles will be migrated and leak out from the specimen in each seepage experiments, and more fine particles will leak out resulting in bigger porosity with high hydraulic pressure. 


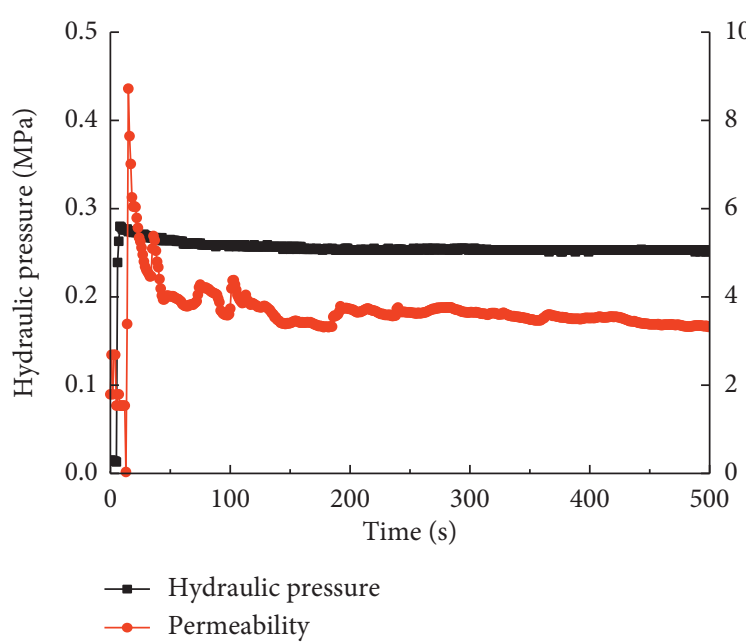

(a)

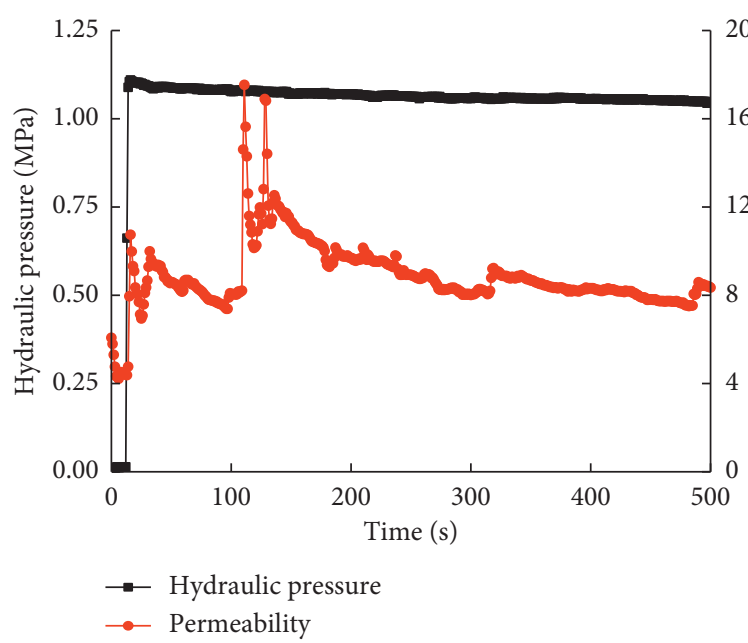

(c)

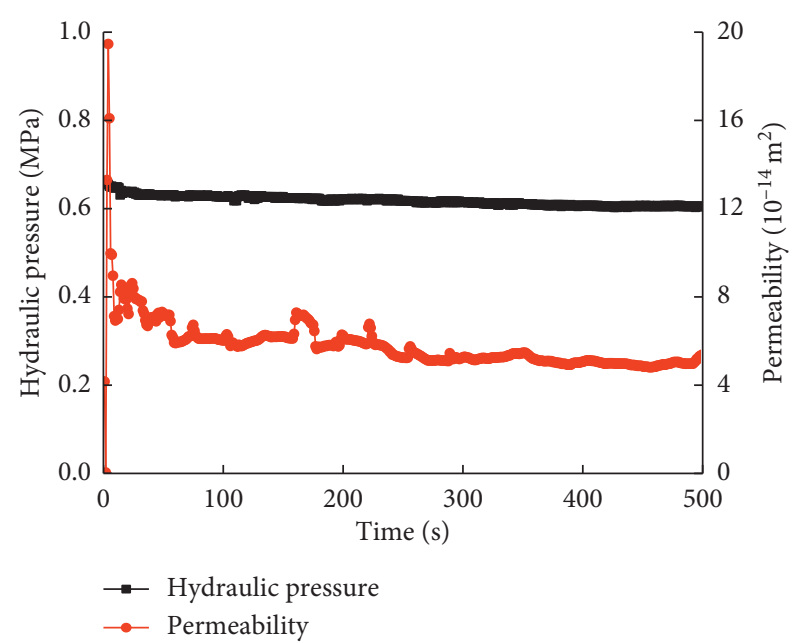

(b)

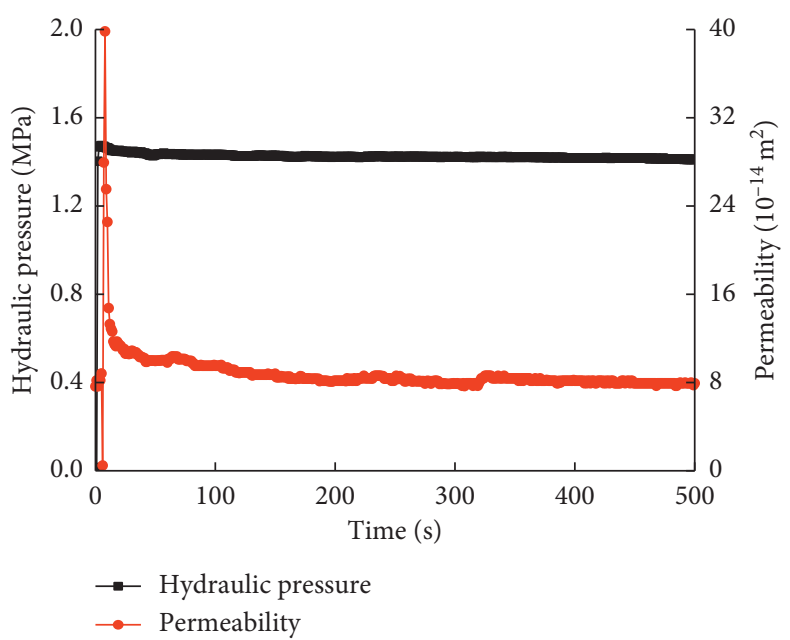

(d)

FIGURE 10: Hydraulic pressure and permeability variation curves of third group specimens with time. (a) $0.3 \mathrm{MPa}$. (b) $0.7 \mathrm{MPa}$. (c) $1.1 \mathrm{MPa}$. (d) $1.5 \mathrm{MPa}$.

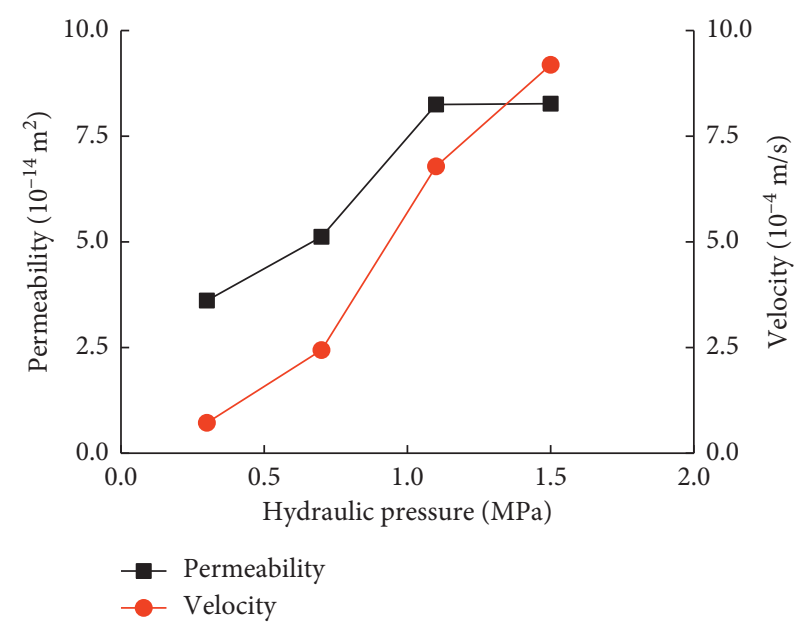

FIGURE 11: Permeability and velocity variation curves with hydraulic pressure.

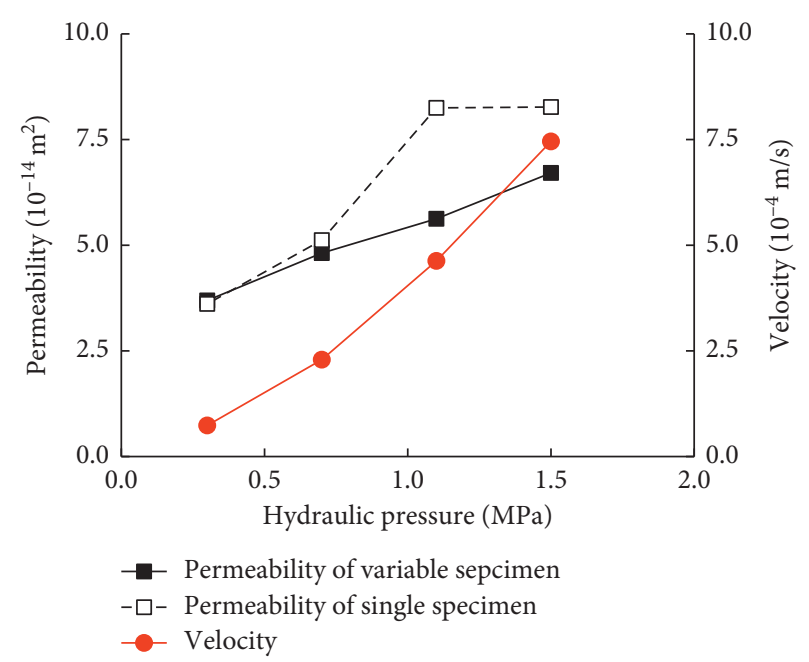

FIGURE 12: Permeability and velocity different specimens with same particle size variation curves with hydraulic pressure. 
However, the permeability increase amplitude of variable specimen was less than that of single specimen. It indicated that the porosity of specimen will further increase with application of repeated hydraulic pressure.

\section{Conclusion}

A self-developed seepage test system is used to study the seepage property of crushed mudstone specimens in this paper. The following conclusions can be drawn from the experimental results:

(1) In the initial stage of seepage experiments of crushed rock mass, water hammer effect exists, and hydraulic pressure increases rapidly. After that, the seepage tends to be stable, and the hydraulic pressure and flow rate remain basically unchanged. In some stages of individual experiments, seepage mutation phenomena such as rapid decrease of hydraulic pressure and increase of flow rate will occur.

(2) The permeability of crushed mudstone is on the order of $10^{-14} \mathrm{~m}^{2} \sim 10^{-13} \mathrm{~m}^{2}$. Under the condition of constant porosity and hydraulic pressure, fine particles expanding with water and less effective seepage pore in the small particle size range number result in the permeability of the specimen increasing with particle size range number.

(3) Under the condition of constant particle size and hydraulic pressure, permeability increases with porosity. In order to find out the criterion of permeability and porosity, the experimental results are fitted to three models developed by predecessors, and the fitting results show (4) is applicable to the experimental results in this paper.

(4) Permeability increases with hydraulic pressure whether one crushed mudstone specimen with progressive hydraulic pressure or different specimens with variable hydraulic pressure. More fine particles leak out from the specimen with repeated application of hydraulic pressure on one specimen, so the permeability of one specimen is bigger than that of different specimens under the condition of same hydraulic pressure.

\section{Symbols}

$A_{s}$ : Cross-section area of permeameter, $\mathrm{m}^{2}$

$h$ : The height of the crushed rock specimen, $\mathrm{m}$

$i$ : The time series, 1

$j$ : The crushed rock specimen number, 1

$k$ : The permeability of crushed rock, $\mathrm{m}^{2}$

$k_{0}$ : The minimum permeability of second specimen group, $\mathrm{m}^{2}$

$M$ : The gushed water mass, $\mathrm{kg}$

$p$ : The hydraulic pressure, $\mathrm{MPa}$

$t$ : Time, $\mathrm{s}$

$V_{b}$ : Crushed rock volume, $\mathrm{m}^{3}$

$v:$ The flow velocity of the water, $\mathrm{m} / \mathrm{s}$

$\rho$ : Water density, $\mathrm{kg} / \mathrm{m}^{3}$ $\mu$ : The dynamic viscosity of water, Pa.s

$\varphi$ : The porosity of crushed rock, 1

$\varphi_{0}$ : The minimum porosity of second specimen group, 1 .

\section{Data Availability}

The raw/processed data required to reproduce these findings cannot be shared at this time as the data also form part of an ongoing study.

\section{Conflicts of Interest}

The authors declare that they have no conflicts of interest to this work.

\section{Acknowledgments}

The work was supported by the National Natural Science Foundation of China (Nos. 41807209, 51778215, and 51708185), the Young Teacher Foundation of HPU (Grant number: 2019XQG-19), the Henan Provincial Youth Talent Promotion Program (no. 2020HYTP003), and the Doctor Foundation of Henan Polytechnic University (Nos. B2017-51 and B2017-53). The authors want to acknowledge these financial assistances.

\section{References}

[1] T. H. Yang, P. Jia, W. H. Shi, P. T. Wang, H. L. Liu, and Q. L. Yu, "Seepage-stress coupled analysis on anisotropic characteristics of the fractured rock mass around roadway," Tunnelling and Underground Space Technology, vol. 43, no. 7, pp. 11-19, 2014.

[2] Z. Q. Yue and Q. Xu, "Fundamental drawbacks and disastrous consequences of current geotechnical safety design theories for slopes," Chinese Journal of Geotechnical Engineering, vol. 36, no. 9, pp. 1601-1606, 2014, in Chinese.

[3] D. Boldini and A. Graziani, "Remarks on axisymmetric modelling of deep tunnels in argillaceous formations II: fissured argillites," Tunnelling and Underground Space Technology, vol. 28, no. 3, pp. 80-89, 2012.

[4] N. Koronakis, P. Kontothanassis, N. Kazilis, and N. Gikas, "Stabilization measures for shallow tunnels with ongoing translational movements due to slope instability," Tunnelling and Underground Space Technology, vol. 19, no. 4-5, p. 495, 2004.

[5] M. G. Sweetenham, R. M. Maxwell, and P. M. Santi, "Assessing the timing and magnitude of precipitation-induced seepage into tunnels bored through fractured rock," Tunnelling and Underground Space Technology, vol. 65, pp. 62-75, 2017.

[6] L. C. Li, T. H. Yang, Z. Z. Liang, W. C. Zhu, and C. A. Tang, "Numerical investigation of groundwater outbursts near faults in underground coal mines," International Journal of Coal Geology, vol. 85, no. 3-4, pp. 276-288, 2011.

[7] T. H. Yang, J. Liu, W. C. Zhu, D. Elsworth, L. G. Tham, and C. A. Tang, "A coupled flow-stress-damage model for groundwater outbursts from an underlying aquifer into mining excavations," International Journal of Rock Mechanics and Mining Sciences, vol. 44, no. 1, pp. 87-97, 2007.

[8] W. Liu, X. Fei, and J. Fang, "Rules for confidence intervals of permeability coefficients for water flow in over-broken rock 
mass," International Journal of Mining Science and Technology, vol. 22, no. 1, pp. 29-33, 2012.

[9] X. X. Miao, S. C. Li, and X. W. Huang, "Experimental study of seepage properties of non-darcy flow in granular gangues," Journal of University of Mining and Technology, vol. 16, no. 2, pp. 105-109, 2006, in Chinese.

[10] X.-x. Miao, S.-c. Li, and Z.-q. Chen, "Bifurcation and catastrophe of seepage flow system in broken rock," Mining Science and Technology (China), vol. 19, no. 1, pp. 1-7, 2009, in Chinese.

[11] X. Miao, S. Li, Z. Chen, and W. Liu, "Experimental study of seepage properties of broken sandstone under different porosities," Transport in Porous Media, vol. 86, no. 3, pp. 805-814, 2011.

[12] H. Kong, Z. Chen, L. Wang, and H. Shen, "Experimental study on permeability of crushed gangues during compaction," International Journal of Mineral Processing, vol. 124, pp. 95101, 2013.

[13] D. Ma, H. Y. Duan, J. F. Liu, X. B. Li, and Z. L. Zhou, “The role of gangue on the mitigation of mining-induced hazards and environmental pollution: an experimental investigation," Science of The Total Environment, vol. 664, pp. 636-448, 2019.

[14] D. Ma, X. X. Miao, G. H. Jiang, H. B. Bai, and Z. Q. Chen, “An experimental investigation of permeability measurement of water flow in crushed rocks," Transport in Porous Media, vol. 105, no. 3, pp. 571-595, 2014.

[15] S. J. Garner and R. J. Fannin, "Understanding internal erosion: a decade of research following a sinkhole event," International Journal on Hydropower and Dams, vol. 17, no. 3, pp. 93-98, 2010.

[16] D. Marot, F. Bendahmane, F. Rosquoet, and A. Alexis, "Internal flow effects on isotropic confined sand-clay mixtures," Soil and Sediment Contamination: An International Journal, vol. 18, no. 3, pp. 294-306, 2009.

[17] L. Ke and A. Takahashi, "Strength reduction of cohesionless soil due to internal erosion induced by one-dimensional upward seepage flow," Soils and Foundations, vol. 52, no. 4, pp. 698-711, 2012.

[18] R. Moffat, R. J. Fannin, and S. J. Garner, "Spatial and temporal progression of internal erosion in cohesionless soil," Canadian Geotechnical Journal, vol. 48, no. 3, pp. 399-412, 2011.

[19] G. Xie, Z. Yin, L. Wang, Z. Hu, and C. Zhu, "Effects of gas pressure on the failure characteristics of coal," Rock Mechanics and Rock Engineering, vol. 50, no. 7, pp. 1711-1723, 2017.

[20] Z. Q. Yin, Z. X. Hu, Z. D. Wei et al., "Assessment of blastinginduced ground vibration in an open-pit mine under different rock properties," Advances in Civil Engineering, vol. 2018, Article ID 4603687, 10 pages, 2018.

[21] Z. Yin, W. Chen, H. Hao et al., "Dynamic compressive test of gas-containing coal using a modified split hopkinson pressure bar system," Rock Mechanics and Rock Engineering, vol. 53, no. 2, pp. 1-15, 2019.

[22] A. Aydin, R. I. Borja, and P. Eichhubl, "Geological and mathematical framework for failure modes in granular rock," Journal of Structural Geology, vol. 28, no. 1, pp. 83-98, 2006.

[23] L. Z. Wang, Z. Q. Chen, and H. L. Kong, "Influences on penetration laws of broken mudstone with mass loss from talbol power exponents," Electronic Journal of Geotechnical Engineering, vol. 19, pp. 3681-3692, 2014.

[24] D. Ma, X. X. Miao, H. B. Bai et al., "Impact of particle transfer on flow properties of crushed mudstones," Environmental Earth Sciences, vol. 75, no. 7, p. 593, 2016.

[25] J. Wu, G. Han, M. Feng et al., "Mass-loss effects on the flow behavior in broken argillaceous red sandstone with different particle-size distributions," Comptes Rendus Mécanique, vol. 347, no. 6, pp. 504-523, 2019.

[26] S. N. Rogak and R. C. Flagan, "Stokes drag on self-similar clusters of spheres," Journal of Colloid and Interface Science, vol. 134, no. 1, pp. 206-218, 1990.

[27] S. Veerapaneni and M. R. Wiesner, "Hydrodynamics of fractal aggregates with radially varying permeability," Journal of Colloid and Interface Science, vol. 177, no. 1, pp. 45-57, 1996.

[28] D. J. Lee, G. W. Chen, Y. C. Liao, and C. C. Hsieh, "On the free-settling test for estimating activated sludge floc density," Water Research, vol. 30, no. 3, pp. 541-550, 1996.

[29] D. Ma, M. Rezania, H.-S. Yu, and H.-B. Bai, "Variations of hydraulic properties of granular sandstones during water inrush: effect of small particle migration," Engineering $\mathrm{Ge}$ ology, vol. 217, pp. 61-70, 2017. 